\title{
Size Effect in the Oxidation-Reduction Processes of Platinum Particles Supported onto Silicon Dioxide
}

\author{
M. Yu. Smirnov ${ }^{a, *}$, A. V. Kalinkin ${ }^{a}$, E. I. Vovk ${ }^{a, b}$, and V. I. Bukhtiyarov ${ }^{a}$ \\ ${ }^{a}$ Boreskov Institute of Catalysis, Siberian Branch, Russian Academy of Sciences, Novosibirsk, 630090 Russia \\ ${ }^{b}$ Chemistry Department, Bilkent University, 06800 Bilkent, Ankara, Turkey \\ *e-mail: smirnov@catalysis.ru \\ Received January 14, 2015
}

\begin{abstract}
The interaction of the $\mathrm{Pt} / \mathrm{SiO}_{2}$ model catalysts as thin films on the surface of tantalum supports with a mixture of $\mathrm{NO}+\mathrm{O}_{2}(1: 1)$ was studied by X-ray photoelectron spectroscopy. The pressure of the reaction mixture was varied from 6 to $64 \mathrm{mbar}$, and the temperature was varied from room temperature to $500^{\circ} \mathrm{C}$. Two types of the catalysts, in which the $\mathrm{Pt} / \mathrm{Si}$ atomic ratios were $\sim 0.1$ and $\sim 0.3(0.1-\mathrm{Pt} / \mathrm{SiO}$ and $0.3-\mathrm{Pt} / \mathrm{SiO}$, respectively) according to the XPS data, were studied. In $0.1-\mathrm{Pt} / \mathrm{SiO}_{2}$, the particles of platinum predominantly had a size from 1 to $2.5 \mathrm{~nm}$; a wide Pt particle size distribution in a range from 1 to $15 \mathrm{~nm}$ with a maximum at $\sim 4 \mathrm{~nm}$ was characteristic of $0.3-\mathrm{Pt} / \mathrm{SiO}_{2}$. The interaction of all of the samples with $\mathrm{NO}+\mathrm{O}_{2}$ at room temperature led to the dissolution of oxygen atoms in the bulk of platinum metal particles. As the reaction temperature was increased, $\mathrm{PtO}_{x}$ platinum oxide particles were formed: from small $\mathrm{Pt}$ particles in $0.1-\mathrm{Pt} / \mathrm{SiO} 2$ at $300^{\circ} \mathrm{C}$ and from larger particles in $0.3-\mathrm{Pt} / \mathrm{SiO}_{2}$ at $400-500^{\circ} \mathrm{C}$. It was established that the reactivity of platinum oxide particles toward hydrogen also depended on the particle size. The small particles of platinum oxide were converted into platinum metal under the action of hydrogen $(16 \mathrm{mbar})$ at $300^{\circ} \mathrm{C}$. The coarse particles of $\mathrm{PtO}_{x}$ in the samples of $0.3-\mathrm{Pt} / \mathrm{SiO}_{2}$ were reduced much more easily starting with room temperature.
\end{abstract}

Keywords: supported model catalysts, $\mathrm{NO}+\mathrm{O}_{2}$, hydrogen, platinum oxides, $\mathrm{X}$-ray photoelectron spectroscopy

DOI: $10.1134 / \mathrm{S} 0023158415060129$

\section{INTRODUCTION}

The oxidation number of platinum is a factor responsible for the activity of supported platinum catalysts. It was established that, in the $\mathrm{NO}_{x}$ storage reduction (NSR) systems, which are used for the neutralization of nitrogen oxides in exhaust gases, the catalyst loses its activity in the course of a key stage of the process: the oxidation of $\mathrm{NO}$ into $\mathrm{NO}_{2}$, when platinum particles, which are the constituents of the catalyst, are converted into an oxidized state under the action of a reaction atmosphere. The ease of the conversion of supported platinum into the particles of platinum oxides depends on the nature of the support, the temperature, the composition of a reaction atmosphere, and the dispersity of platinum.

Lee and Kung [1] considered an example of the effect exerted by the size of platinum particles on their oxidation in the composition of a $\mathrm{Pt} / \gamma-\mathrm{Al}_{2} \mathrm{O}_{3}$ catalyst. In a comparison of catalysts with platinum dispersity of 4.4 and $82 \%$ in the reaction of NO oxidation, it was found that the specific activity of the less dispersed catalyst was higher by two orders of magnitude. The reason for this behavior is that coarser platinum particles are less inclined to oxidation; therefore, platinum remains in an active metallic state in the course of reaction in the case of a coarsely dispersed catalyst. Olsson and Fridell [2] found that the rate of $\mathrm{NO}_{2}$ dissociation gradually decreased in the course of the interaction of $\mathrm{Pt} / \mathrm{Al}_{2} \mathrm{O}_{3}$ with $\mathrm{NO}_{2}$ at $350^{\circ} \mathrm{C}$. With the use of X-ray photoelectron spectroscopy (XPS), it was established that the rate decreased due to the formation of platinum oxides. Because of this, the rate of catalyst deactivation in a reaction atmosphere containing $\mathrm{NO}_{2}$ increased with the dispersity of platinum because smaller platinum particles were more easily converted into oxides. Benard et al. [3] found an analogous manifestation of the size effect for the $\mathrm{Pt} / \mathrm{SiO}_{2}$ catalysts: activity in the reaction of $\mathrm{NO}$ oxidation increased with the particle size of supported platinum. Mulla et al. [4] noted a fourfold increase in the activity of $\mathrm{Pt} / \mathrm{Al}_{2} \mathrm{O}_{3}$ in the oxidation of $\mathrm{NO}$ at $300^{\circ} \mathrm{C}$ in a reaction atmosphere containing $300 \mathrm{ppm}$ of $\mathrm{NO}+$ 170 ppm of $\mathrm{NO}_{2}+10 \% \mathrm{O}_{2}$ (the balance $\mathrm{N}_{2}$ ) once a freshly prepared sample was subjected to sintering. Villani et al. [5] found the influence of the particle size of platinum supported onto different oxide carriers in a more complex catalytic process, which occurs with the participation of NO: the oxidation of carbon in an atmosphere containing NO, oxygen, and water vapor. They demonstrated that there is an optimum particle size of platinum for this process, $20-40 \mathrm{~nm}$ (at 3-4\% 
dispersity), which corresponds to an optimum particle size in the reaction of $\mathrm{NO}$ conversion into $\mathrm{NO}_{2}$ in this reaction atmosphere.

Kalinkin et al. [6] used XPS and scanning tunnel microscopy (STM) for studying the interaction of $\mathrm{NO}_{2}$ with the particles of platinum evaporeted onto the surface of highly oriented pyrolytic graphite at room temperature and a pressure of $3 \times 10^{-6}$ mbar. It was found that, under these conditions, only small platinum particles of size $\sim 2.5 \mathrm{~nm}$ underwent oxidation with the formation of $\mathrm{PtO}$ and $\mathrm{PtO}_{2}$ particles, whereas larger particles $(\sim 5.5 \mathrm{~nm})$ remained in a metallic state.

Previously, the interaction of the $\mathrm{Pt} / \mathrm{Al}_{2} \mathrm{O}_{3}$ and $\mathrm{Pt} / \mathrm{SiO}_{2}$ thin-film model catalysts with a reaction mixture of 10 mbar of $\mathrm{NO}+10$ mbar of $\mathrm{O}_{2}$ was studied in [7]. The size of platinum particles in the test samples was $1-3 \mathrm{~nm}$. The oxidation of nanosized platinum particles under the action of a reaction atmosphere occurred only at elevated temperatures $\left(\sim 300^{\circ} \mathrm{C}\right)$. Interaction at room temperature also led to a change in the state of platinum particles, which was supposedly caused by the dissolution of oxygen atoms in the bulk of particles with the retention of their metal properties. It was found that oxygen dissolved in the particles of platinum metal entered into reaction with hydrogen much more easily than the particles of platinum oxide. In this work, we carried out a comparative XPS study of two $\mathrm{Pt} / \mathrm{SiO}_{2}$ model systems with different platinum particle size distributions in a reaction with a mixture of NO and oxygen and the subsequent reduction of the oxidized samples in hydrogen in order to examine the effect of particle size on the oxidationreduction processes with the participation of supported platinum particles.

\section{EXPERIMENTAL}

The preparation of model catalyst samples, their treatment in a reaction atmosphere, and the measurement of XPS spectra were carried out on a VG ESCA-3 instrument (Vacuum Generators, the United Kingdom) at a residual pressure of $<5 \times 10^{-9}$ mbar in the analytical chamber of the instrument. The XPS spectra were recorded with the use of the $K \alpha_{1,2} \mathrm{X}$-ray line $(h v=1253.6 \mathrm{eV})$ of nonmonochromatic $\mathrm{Mg} K \alpha$ radiation at an X-ray tube voltage of $8.5 \mathrm{kV}$ and a current intensity of $20 \mathrm{~mA}$. The pass energy of the analyzer corresponded to the parameter $\mathrm{HV}=20 \mathrm{~V}$. Before the experiments, the scale of binding energies of the spectrometer was calibrated based on the positions of the gold $\mathrm{Au} 4 f_{7 / 2}(84.0 \mathrm{eV})$ and copper $\mathrm{Cu} 2 p_{3 / 2}(932.6 \mathrm{eV})$ lines. The photoemission spectra were processed after Shirley background subtraction. In the determination of the exact values of the binding energies of photoemission lines, the $\mathrm{Si} 2 p$ line of silicon dioxide, whose binding energy was taken equal to $103.4 \mathrm{eV}$, was used as an internal standard. In this calibration procedure, the binding energy of the $\mathrm{C} 1 s$ line of amorphous carbon, which was accumulated on the sample surface in the course of spectral measurements, varied within a range of $284.8-285.0 \mathrm{eV}$.

The samples of model catalysts were obtained in the preparation chamber of the spectrometer in accordance with a published procedure [8-10]. The thin films of $\mathrm{SiO}_{2}$ were synthesized on the surface of tantalum foil by the vacuum evaporation of silicon followed by annealing in oxygen at a pressure of $10^{-5}$ mbar and a temperature of $300^{\circ} \mathrm{C}$. The sample was heated by passing the current through the tantalum foil; the temperature was measured with the aid of a chromelalumel thermocouple welded to the reverse side of the foil. The $\mathrm{SiO}_{2}$ films formed ensured the almost complete screening of the photoemission lines of tantalum in the XPS spectra. This allowed us to conclude that the thickness of $\mathrm{SiO}_{2}$ films was no smaller than $10 \mathrm{~nm}$. Platinum was supported onto the surface of silicon dioxide by thermal evaporation in a vacuum. The platinum content of the samples was determined based on the intensity ratio of the photoelectron lines Pt $4 f$ and $\mathrm{Si} 2 p$, from which the $\mathrm{Pt} / \mathrm{Si}$ atomic ratio was calculated taking into account atomic sensitivity factors [11]. In the $\mathrm{Pt} 4 f$ spectra of the freshly prepared $\mathrm{Pt} / \mathrm{SiO}_{2}$ samples, the spin-orbital components $\mathrm{Pt} 4 f_{7 / 2}$ and $\mathrm{Pt} 4 f_{5 / 2}$ had an asymmetric shape with a tail elongated toward higher binding energies; this shape is characteristic of platinum metal. Along with the binding energy $E_{\mathrm{b}}\left(\mathrm{Pt} 4 f_{7 / 2}\right)$, the degree of line asymmetry, which is calculated in accordance with a published procedure [7], is important for evaluating the chemical state of platinum. In platinum oxides, the $\mathrm{Pt} 4 f_{7 / 2}$ and $\mathrm{Pt} 4 f_{5 / 2}$ lines are symmetrical.

We prepared and studied two series of samples with the relative platinum concentrations $\mathrm{Pt} / \mathrm{Si} \approx$ $0.1\left(0.1-\mathrm{Pt} / \mathrm{SiO}_{2}\right.$ samples) and $\mathrm{Pt} / \mathrm{Si} \approx 0.3\left(0.3-\mathrm{Pt} / \mathrm{SiO}_{2}\right.$ samples). The model catalyst samples were treated with a mixture of $\mathrm{NO}+\mathrm{O}_{2}$ (molar ratio, $\left.1: 1\right)$ in the preparation chamber at $30-500^{\circ} \mathrm{C}$ and a pressure of 6-64 mbar. Then, the samples were transferred into the analytical chamber without contact with the atmosphere for the recording of XPS spectra. After treatment in the mixture of $\mathrm{NO}+\mathrm{O}_{2}$, the samples were reduced in hydrogen at $30-300^{\circ} \mathrm{C}$ and a pressure of 16 mbar.

The particle size of platinum supported on $\mathrm{SiO}_{2}$ was estimated by transmission electron microscopy (TEM) on a JEM-2010 instrument (JEOL, Japan) at an accelerating voltage of $200 \mathrm{kV}$ and a lattice resolution of $0.14 \mathrm{~nm} .^{1}$ For this purpose, the $\mathrm{Pt} / \mathrm{SiO}_{2}$ samples with the $\mathrm{Pt} / \mathrm{Si}$ atomic ratios of $\sim 0.1$ and $\sim 0.3$ were prepared in accordance with the procedure described above by the sequential supporting of $\mathrm{SiO}_{2}$ and Pt onto carbon films on copper gauzes, which are traditionally used as substrates in TEM.

\footnotetext{
${ }^{1}$ The TEM measurements and image processing were performed by V.I. Zaikovskii and E.Yu. Gerasimov, the staff members of the Boreskov Institute of Catalysis, Siberian Branch, Russian Academy of Sciences.
} 
(a)

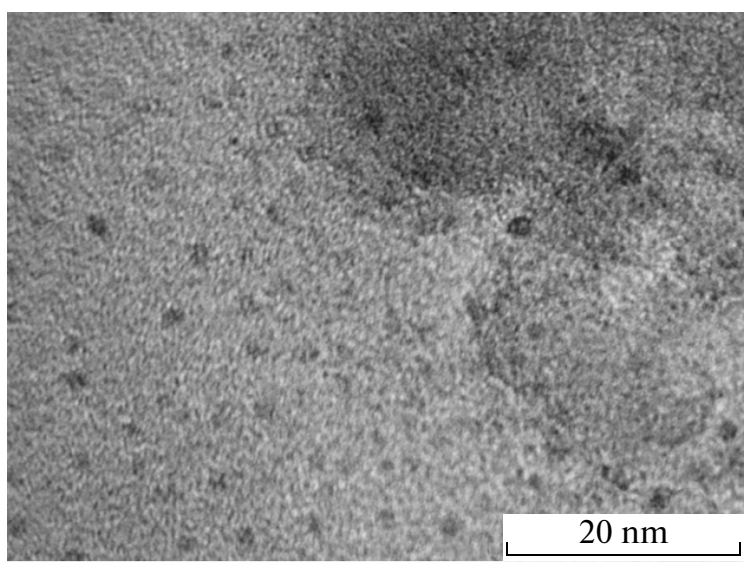

(c)

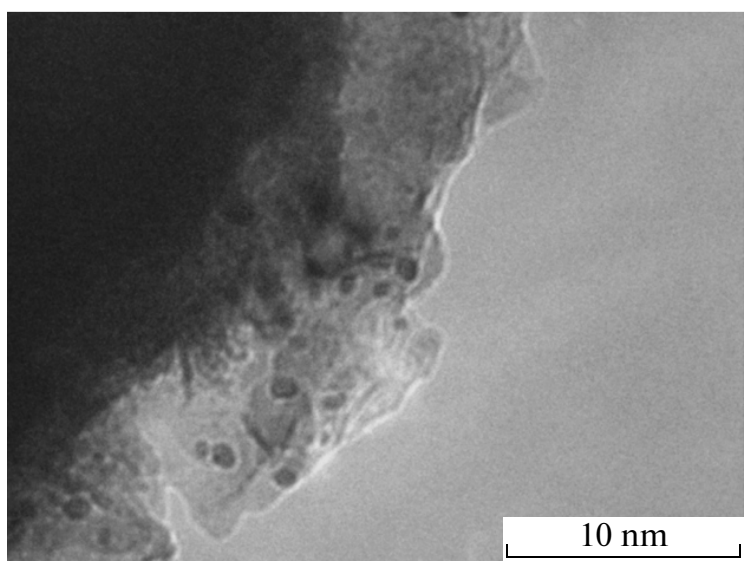

(b)

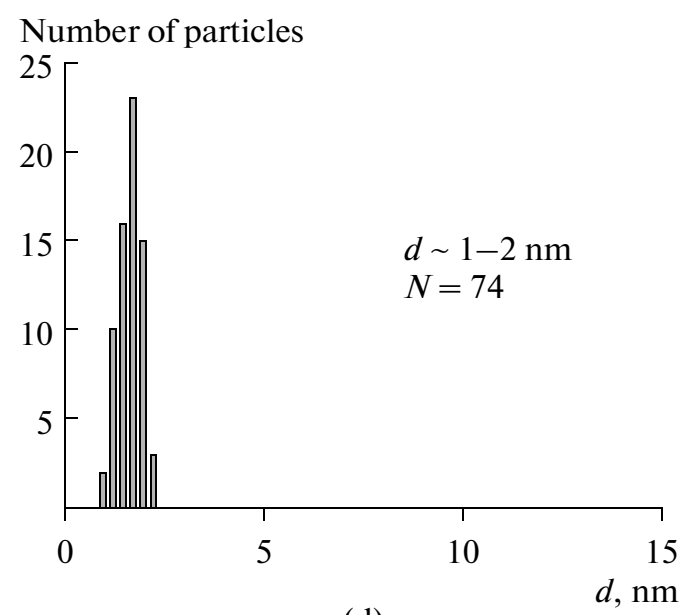

(d)

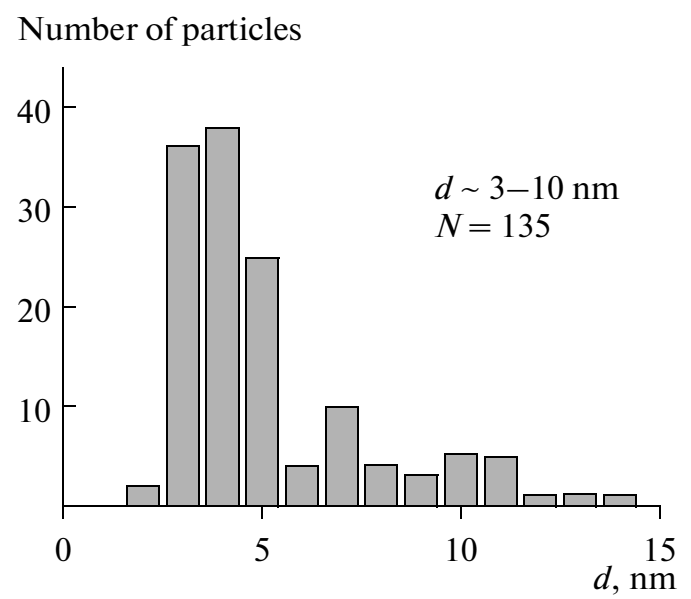

Fig. 1. TEM images of the thin-film (a) $0.1-\mathrm{Pt} / \mathrm{SiO}_{2}$ and (c) $0.3-\mathrm{Pt} / \mathrm{SiO}_{2}$ samples on carbon substrates and (b, d) the particle size distributions of platinum, respectively. $N$ is the total number of particles taken into account in the plotting of the distributions.

\section{RESULTS AND DISCUSSION}

\section{1-Pt/SiO ${ }_{2}$ and 0.3-Pt/SiO ${ }_{2}$ Samples in the Initial State}

Figure 1 shows the TEM micrographs of the fragments of test model catalysts prepared on the substrates of a perforated carbon film. In the $0.1-\mathrm{Pt} / \mathrm{SiO}_{2}$ sample with a relatively low platinum content (the $\mathrm{Pt} / \mathrm{Si}$ atomic ratio $\approx 0.1$ ) (Fig. 1a), the Pt particles have a narrow size distribution (Fig. 1b); in this case, the size of the majority of them falls in a range from 1 to $2.5 \mathrm{~nm}$. In the $0.3-\mathrm{Pt} / \mathrm{SiO}_{2}$ sample with a higher platinum content (the $\mathrm{Pt} / \mathrm{Si}$ atomic ratio $\approx 0.3$ ) (Fig. $1 \mathrm{c}$ ), the evaporated metal particles have a wide size distribution (Fig. 1d). The distribution curve exhibits an asymmetrical peak with a maximum at $\sim 4 \mathrm{~nm}$ and a strongly elongated tail toward greater particle sizes. A considerable portion of particles falls in a range from
3 to $5 \mathrm{~nm}$, but particles whose size reaches $15 \mathrm{~nm}$ are also observed.

According to the XPS data, the binding energies $E_{\mathrm{b}}\left(\mathrm{Pt} 4 f_{7 / 2}\right)$ in the $0.1-\mathrm{Pt} / \mathrm{SiO}_{2}$ and $0.3-\mathrm{Pt} / \mathrm{SiO}_{2}$ samples are 72.2 and $71.6 \mathrm{eV}$, respectively. The values obtained are noticeably different from the binding energy of bulk platinum metal, which is $71.2 \mathrm{eV}$. Nevertheless, based on the sample preparation method and taking into account the asymmetric line shape characteristic of bulk platinum in the Pt $4 f$ spectrum, we assume that platinum occurs in a metallic state. The shift of the Pt $4 f_{7 / 2}$ binding energy relative to a tabular value for platinum metal observed in the samples is explained by the final state effect related to photoemission from supported small metal particles. It is believed that the shift is caused by the fact that a positive hole at the $4 f$ level, which results from photoemission, in the particles is screened less effectively than in the bulk metal; in this case, the smaller the particle size, the greater 
(a)

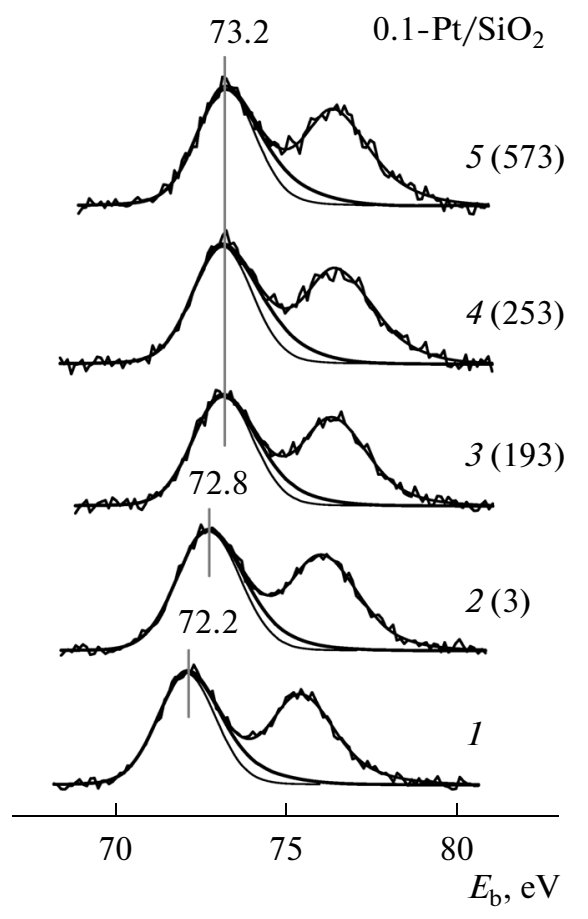

(b)

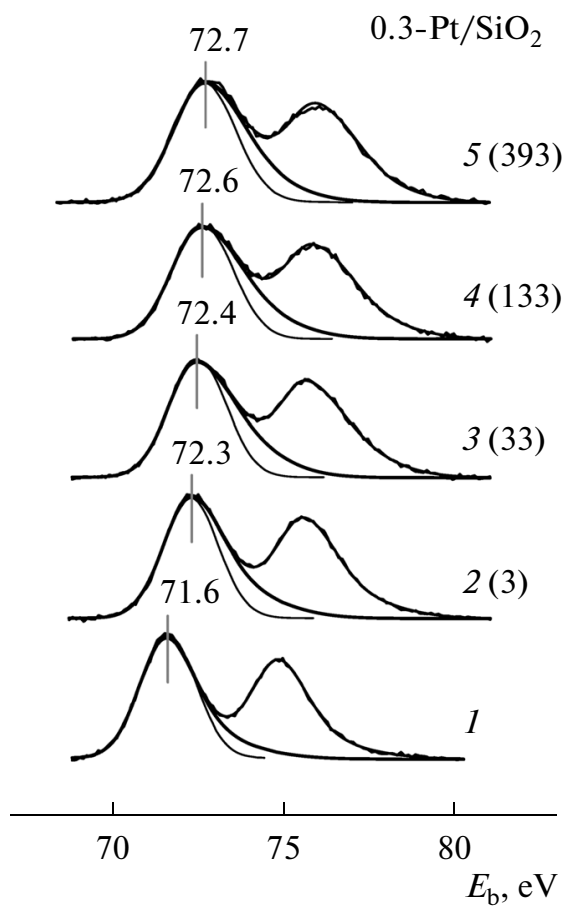

Fig. 2. Pt $4 f$ XPS spectra of the (a) $0.1-\mathrm{Pt} / \mathrm{SiO}_{2}$ and (b) $0.3-\mathrm{Pt} / \mathrm{SiO}_{2}$ samples (1) before and after interaction with a mixture of $\mathrm{NO}+\mathrm{O}_{2}$ at room temperature and exposures (mbar min) indicated in parentheses.

the shift [12]. In addition to the lines of platinum, the lines of silicon ( $\mathrm{Si} 2 p, 103.4 \mathrm{eV}$ and $\mathrm{Si} 2 s, 154.2 \mathrm{eV}$ ), silicon dioxide oxygen $(\mathrm{O} 1 s, 532.5 \mathrm{eV})$, and carbon from the substrate $(\mathrm{C} 1 s, 284.9 \mathrm{eV})$ can also be seen in the spectra. Analogous $\mathrm{Pt} 4 f, \mathrm{Si} 2 p, \mathrm{Si} 2 s$, and $\mathrm{O} 1 s$ spectra were obtained for the samples prepared on the tantalum substrates.

\section{Interaction of Platinum Particles with $\mathrm{NO}+\mathrm{O}_{2}$ at Room Temperature}

The samples prepared on the tantalum substrates were used in the study of the interaction of the $\mathrm{Pt} / \mathrm{SiO}_{2}$ model systems with the reaction mixture $\left(\mathrm{NO}+\mathrm{O}_{2}\right)$. The treatment of the samples in the reaction mixture did not lead to the appearance of lines in the N1s region and to changes in the $\mathrm{O} 1 s$ region. The most significant changes observed in the spectra are related to a change in the state of platinum. Figure 2 shows the Pt $4 f$ spectra measured after the contact of the 0.1Pt $/ \mathrm{SiO}_{2}$ (Fig. 2a) and 0.3-Pt/SiO ${ }_{2}$ samples (Fig. 2b) with the reaction mixture at room temperature. In each of the above spectra, a heavy line shows the asymmetrically shaped $\mathrm{Pt} 4 f_{7 / 2}$ component having a tail elongated toward greater binding energies. This asymmetric shape is characteristic of the photoemission lines in the spectra of platinum group metals; it is caused by the high density of $d$ electrons at the Fermi level in them [13, 15]. To more clearly visualize the asymmetry, a corresponding symmetrical line was drawn for each of the spectra in Fig. 2 by reflecting the left-hand half of an experimental component with respect to a vertical line that passes through a maximum.

Table 1 and Fig. 2a show changes in the parameters of the Pt $4 f$ line in the course of reaction of the 0.1$\mathrm{Pt} / \mathrm{SiO}_{2}$ sample with $\mathrm{NO}+\mathrm{O}_{2}$ at room temperature. The total exposures given in the third column are the sums of the products of reaction mixture pressures (column 1) and contact times (column 2). Initially, $E_{\mathrm{b}}\left(\mathrm{Pt}_{4} f_{7 / 2}\right)$ rapidly increased with exposure, and it increased by $\sim 1.0 \mathrm{eV}$ at an exposure of $193 \mathrm{mbar}$ min. The value of $E_{\mathrm{b}}\left(\mathrm{Pt} 4 f_{7 / 2}\right)$ remained unchanged as the exposure was further increased. The line width and the $\mathrm{Pt} / \mathrm{Si}$ atomic ratio did not change in the course of interaction, and the line shape remained asymmetric. Previously, a similar behavior of the XPS spectra of platinum in the model samples was interpreted as the dissolution of oxygen atoms formed upon the dissociation of $\mathrm{NO}\left(\mathrm{NO}_{2}\right)$ in the bulk of supported metal particles [7, 8]. It is assumed that, in this case, platinum retained its metallic state, and an increase in the value of $E_{\mathrm{b}}\left(\mathrm{Pt} 4 f_{7 / 2}\right)$ was caused by electron transfer from platinum atoms to dissolved oxygen atoms. Because the $\mathrm{Pt} / \mathrm{Si}$ atomic ratio remained almost unchanged under the given conditions, it is believed that the dissolution of oxygen does not lead to the agglomeration 
Table 1. Changes in $\mathrm{Pt} 4 f_{7 / 2}$ line parameters and $\mathrm{Pt} / \mathrm{Si}$ atomic ratios upon the contact of the $\mathrm{Pt} / \mathrm{SiO}_{2}$ samples with a mixture of $\mathrm{NO}+\mathrm{O}_{2}$ at room temperature

\begin{tabular}{|c|c|c|c|c|c|c|}
\hline Pressure, mbar & $\begin{array}{c}\text { Contact time, } \\
\text { min }\end{array}$ & $\begin{array}{c}\text { Total exposure } \\
\text { mbar min }\end{array}$ & $E_{\mathrm{b}}, \mathrm{eV}$ & $\mathrm{FWHM}^{*}, \mathrm{eV}$ & $\mathrm{Pt} / \mathrm{Si}$ & Asymmetry \\
\hline \multicolumn{7}{|c|}{$0.1-\mathrm{Pt} / \mathrm{SiO}_{2}$} \\
\hline 0 & 0 & 0 & 72.2 & 2.2 & 0.10 & 1.34 \\
\hline 6 & 0.5 & 3 & 72.8 & 2.3 & 0.11 & 1.23 \\
\hline 6 & 5 & 33 & 73.1 & 2.2 & 0.10 & 1.27 \\
\hline 12 & 5 & 93 & 73.1 & 2.3 & 0.11 & 1.24 \\
\hline 20 & 5 & 193 & 73.2 & 2.2 & 0.10 & 1.24 \\
\hline 20 & 3 & 253 & 73.2 & 2.3 & 0.11 & 1.35 \\
\hline 64 & 5 & 573 & 73.2 & 2.2 & 0.11 & 1.31 \\
\hline \multicolumn{7}{|c|}{$0.3-\mathrm{Pt} / \mathrm{SiO}_{2}$} \\
\hline 0 & 0 & 0 & 71.6 & 2.0 & 0.34 & 1.26 \\
\hline 6 & 0.5 & 3 & 72.3 & 2.2 & 0.34 & 1.53 \\
\hline 6 & 5 & 33 & 72.4 & 2.4 & 0.36 & 1.50 \\
\hline 20 & 5 & 133 & 72.6 & 2.5 & 0.35 & 1.47 \\
\hline 20 & 5 & 233 & 72.6 & 2.5 & 0.37 & 1.48 \\
\hline 32 & 5 & 393 & 72.7 & 2.5 & 0.37 & 1.45 \\
\hline
\end{tabular}

* FWHM is the full width at half maximum.

of particles and does not have a noticeable effect on their size.

The interaction of $0.3-\mathrm{Pt} / \mathrm{SiO}_{2}$ with $\mathrm{NO}+\mathrm{O}_{2}$ at room temperature was also accompanied by a monotonic increase in $E_{\mathrm{b}}\left(\mathrm{Pt} 4 f_{7 / 2}\right)$ as the exposure was increased (Table 1, Fig. 2b). This sample is characterized by a wide platinum particle size distribution (Fig. 1d). It is obvious that, in this case, small particles $(\sim 1-2 \mathrm{~nm})$ behave just as in $0.1-\mathrm{Pt} / \mathrm{SiO}_{2}$; however, it is likely that the contribution of these particles to the integral Pt $4 f$ peak is small. Thus, it is possible to state that, in this case, the basic contribution to the displacement of the Pt $4 f$ line is ensured by relatively large particles $(\sim 3-15 \mathrm{~nm})$, and the dissolution of oxygen in these particles also occurs effectively. Note that, in contrast to the $0.1-\mathrm{Pt} / \mathrm{SiO}_{2}$ sample, upon the contact of $0.3-\mathrm{Pt} / \mathrm{SiO}_{2}$ with the reaction mixture, the $\mathrm{Pt} 4 f$ line was broadened and its maximum was simultaneously shifted (Table 1). In our opinion, this broadening is based on the structure peculiarities of the sample caused by the presence of platinum particles with different sizes on the support surface. It is believed that the saturation concentration of dissolved oxygen depends on particle size. For example, the smaller the particle, the more oxygen atoms per platinum atom can be dissolved. In this case, after the treatment of the $0.3-\mathrm{Pt} / \mathrm{SiO}_{2}$ sample, the $\mathrm{Pt} 4 f$ line in small particles will be more largely shifted than in large particles to cause the broadening of the integral line. As in the 0.1$\mathrm{Pt} / \mathrm{SiO}_{2}$ sample, the absence of changes in the $\mathrm{Pt} / \mathrm{Si}$ atomic ratio indicates that substantial changes in the particle size did not occur upon the interaction of the
$0.3-\mathrm{Pt} / \mathrm{SiO}_{2}$ sample with $\mathrm{NO}+\mathrm{O}_{2}$ at room temperature.

\section{Oxidation of Platinum Particles on Interaction with $\mathrm{NO}+\mathrm{O}_{2}$ at Elevated Temperatures}

Figure 3 shows the $\mathrm{Pt} 4 f$ spectra of the $0.1-\mathrm{Pt} / \mathrm{SiO}_{2}$ (Fig. 3a) and 0.3-Pt/SiO $\mathrm{S}_{2}$ samples (Fig. 3b) after contact with the mixture of $\mathrm{NO}$ and oxygen at elevated temperatures and a pressure of 64 mbar. The bottom spectra in Fig. 3 belong to the samples in the initial state, and they duplicate the bottom spectra in Fig. 2. The spectra arranged directly above them duplicate the top spectra in Fig. 2.

On the interaction of the $0.1-\mathrm{Pt} / \mathrm{SiO}_{2}$ sample with a mixture of $\mathrm{NO}+\mathrm{O}_{2}$, an increase the temperature in a range from room temperature to $200^{\circ} \mathrm{C}$ did not change the position of the Pt $4 f_{7 / 2}$ line (Fig. 3a); this fact indicates the absence of changes in the state of platinum particles. In this case, the line retained its asymmetric shape characteristic of the metallic state, although the degree of asymmetry decreased with temperature (Table 2). The line width also decreased in this case; this was likely due to the gradual leveling of dissolved oxygen concentration in different platinum particles before the stage of the formation of an oxide phase. As judged from small changes in the $\mathrm{Pt} / \mathrm{Si}$ atomic ratio (Table 2), the particle size insignificantly changed in this case.

After treatment at $300^{\circ} \mathrm{C}$, an additional shift of the $\mathrm{Pt} 4 f_{7 / 2}$ line by $\sim 0.4 \mathrm{eV}$ toward greater $E_{\mathrm{b}}$ was observed (Table 2, Fig. 3a). The binding energy of $73.6 \mathrm{eV}$ cor- 
(a)

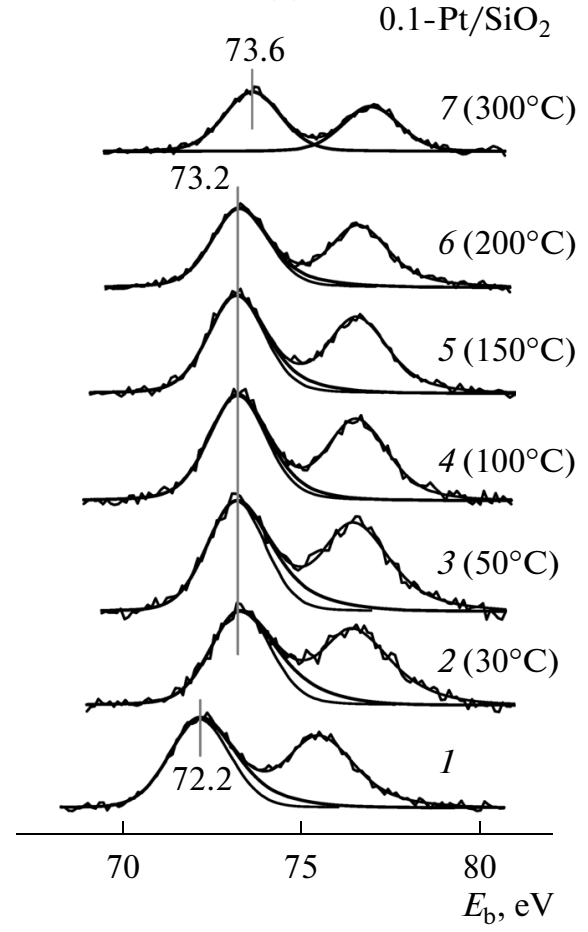

(b)

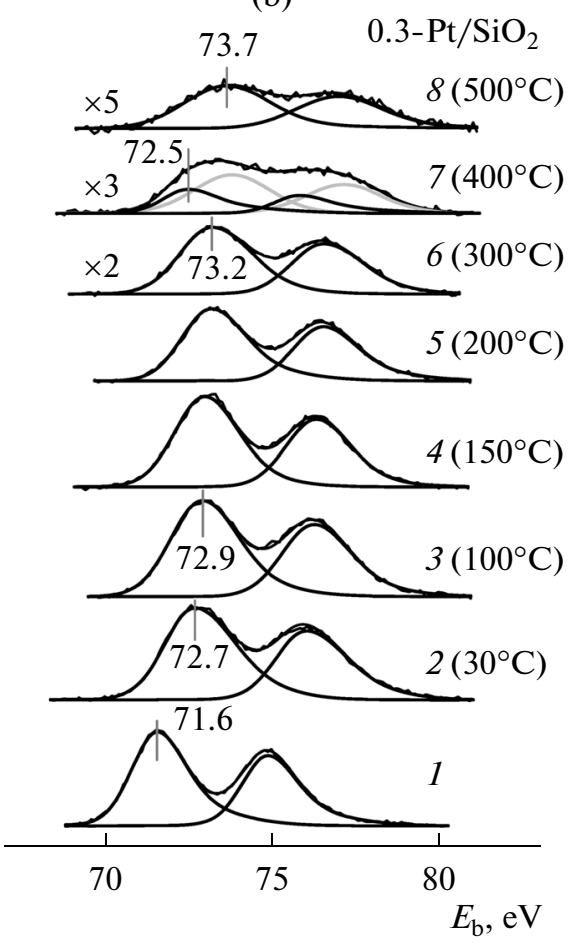

Fig. 3. Pt $4 f$ XPS spectra of the (a) $0.1-\mathrm{Pt} / \mathrm{SiO}_{2}$ and (b) $0.3-\mathrm{Pt} / \mathrm{SiO}_{2}$ samples (1) before and after interaction with a mixture of $\mathrm{NO}+\mathrm{O}_{2}$ at different temperatures.

responds to the oxidized state of platinum. It is difficult to accurately establish the nature of the oxide because a value of $73.6 \mathrm{eV}$ occupies an intermediate position between the values characteristic of the bulk platinum oxides $\mathrm{PtO}$ and $\mathrm{PtO}_{2}$ [15-18]. Subsequently, we designate this state as $\mathrm{PtO}_{x}$. As expected, the Pt4f line became symmetrical upon the formation of platinum oxide particles (Table 2). The $\mathrm{Pt} / \mathrm{Si}$ atomic ratio decreased by a factor of $\sim 2$, as compared with the value that characterized the sample in the initial state (Table 2 ). This can be due to a change in the size and shape of platinum particles upon their transfer into an oxidized state.

For the $0.3-\mathrm{Pt} / \mathrm{SiO}_{2}$ sample in a temperature range from room temperature to $300^{\circ} \mathrm{C}$, the Pt $4 f$ line gradually shifted to the region of high binding energies (Table 2, Fig. 3b). In a temperature range from room temperature to $200^{\circ} \mathrm{C}$, a small narrowing of the Pt $4 f$ line with the retention of a significant degree of asymmetry occurred simultaneously with the shift. This behavior of the sample, which possesses a wide platinum particle size distribution, can be explained as follows: It is obvious that, as in the case of $0.1-\mathrm{Pt} / \mathrm{SiO}_{2}$ with small platinum particles, an oxide phase was not formed in the $0.3-\mathrm{Pt} / \mathrm{SiO}_{2}$ sample at a temperature lower than $200^{\circ} \mathrm{C}$. It is believed that the concentration of dissolved oxygen in the larger particles of platinum increases with temperature. This leads to the leveling of oxygen concentrations in the large and small particles and, as a result, to the narrowing of the Pt $4 f$ line.

Note that, after the reaction performed at $300^{\circ} \mathrm{C}$, a large portion of platinum was not converted into oxide. After the reaction at $400^{\circ} \mathrm{C}$, the shape of the spectrum considerably changed, and it could not be described by one doublet line. In Fig. 3b, a spectrum is decomposed into two doublet lines; the spin-orbital components of one of them are comparatively narrow and have an asymmetric shape (Table 2 ). The binding energy $E_{\mathrm{b}}\left(\mathrm{Pt} 4 f_{7 / 2}\right)$ of this line is 72.5 to $\mathrm{eV}$. This value is close to $E_{\mathrm{b}}\left(\mathrm{Pt} 4 f_{7 / 2}\right)$ after a contact of the sample with the reaction mixture at room temperature. The second line is relatively wide and symmetrical, and the binding energy $E_{\mathrm{b}}\left(\mathrm{Pt} 4 f_{7 / 2}\right)$ corresponding to it is $73.7 \mathrm{eV}$, which is characteristic of the particles of platinum oxide $\left(\mathrm{PtO}_{x}\right)$ [7]. After an increase in the reaction temperature to $500^{\circ} \mathrm{C}$, a spectrum that can be described by one doublet line with binding energy corresponding to oxide particles was obtained (Fig. 3b). The line is broad and almost symmetrical (Table 2). After the reaction at $500^{\circ} \mathrm{C}$, the $\mathrm{Pt} / \mathrm{Si}$ atomic ratio in the 0.3 $\mathrm{Pt} / \mathrm{SiO}_{2}$ sample decreased by almost an order of magnitude (Table 2); this fact suggests a considerable increase in the size of the particles as a result of their agglomeration. 
Table 2. The temperature dependence of $\mathrm{Pt} 4 f_{7 / 2}$ line parameters and $\mathrm{Pt} / \mathrm{Si}$ atomic ratios on the contact of the $\mathrm{Pt} / \mathrm{SiO}_{2}$ samples with a mixture of $\mathrm{NO}+\mathrm{O}_{2}{ }^{*}$

\begin{tabular}{|c|c|c|c|c|c|c|c|c|c|c|}
\hline \multirow[b]{2}{*}{$T,{ }^{\circ} \mathrm{C}$} & \multicolumn{5}{|c|}{$0.1-\mathrm{Pt} / \mathrm{SiO}_{2}$} & \multicolumn{5}{|c|}{$0.3-\mathrm{Pt} / \mathrm{SiO}_{2}$} \\
\hline & state of $\mathrm{Pt}$ & $E_{\mathrm{b}}, \mathrm{eV}$ & $\begin{array}{c}\mathrm{FWHM}^{* *} \\
\mathrm{eV}\end{array}$ & $\mathrm{Pt} / \mathrm{Si}$ & $\begin{array}{l}\text { asym- } \\
\text { metry }\end{array}$ & state of $\mathrm{Pt}$ & $E_{\mathrm{b}}, \mathrm{eV}$ & $\begin{array}{c}\text { FWHM } \\
\mathrm{eV}\end{array}$ & $\mathrm{Pt} / \mathrm{Si}$ & $\begin{array}{l}\text { asym- } \\
\text { metry }\end{array}$ \\
\hline $\begin{array}{l}\text { Initial } \\
\mathrm{Pt} / \mathrm{SiO}_{2}\end{array}$ & $\mathrm{Pt}^{0}$ & 72.2 & 2.2 & 0.10 & 1.35 & $\mathrm{Pt}^{0}$ & 71.6 & 2.0 & 0.34 & 1.52 \\
\hline$\sim 30$ & $\mathrm{Pt}-\mathrm{O}_{\mathrm{dis}} * * *$ & 73.2 & 2.2 & 0.11 & 1.31 & $\mathrm{Pt}-\mathrm{O}_{\mathrm{dis}}$ & 72.7 & 2.5 & 0.37 & 1.45 \\
\hline 50 & $\mathrm{Pt}-\mathrm{O}_{\mathrm{dis}}$ & 73.2 & 2.2 & 0.12 & 1.36 & $\mathrm{Pt}-\mathrm{O}_{\mathrm{dis}}$ & 72.7 & 2.5 & 0.34 & 1.39 \\
\hline 100 & $\mathrm{Pt}-\mathrm{O}_{\mathrm{dis}}$ & 73.2 & 2.0 & 0.10 & 1.14 & $\mathrm{Pt}-\mathrm{O}_{\mathrm{dis}}$ & 72.9 & 2.4 & 0.35 & 1.22 \\
\hline 150 & $\mathrm{Pt}-\mathrm{O}_{\mathrm{dis}}$ & 73.2 & 2.0 & 0.10 & 1.17 & $\mathrm{Pt}-\mathrm{O}_{\mathrm{dis}}$ & 73.0 & 2.3 & 0.30 & 1.24 \\
\hline 200 & $\mathrm{Pt}-\mathrm{O}_{\mathrm{dis}}$ & 73.2 & 1.9 & 0.078 & 1.14 & $\mathrm{Pt}-\mathrm{O}_{\mathrm{dis}}$ & 73.2 & 2.3 & 0.23 & 1.23 \\
\hline 300 & $\mathrm{PtO}_{x}$ & 73.6 & 1.9 & 0.049 & 1.00 & $\mathrm{Pt}-\mathrm{O}_{\mathrm{dis}}$ & 73.2 & 2.6 & 0.13 & 1.22 \\
\hline \multirow{2}{*}{400} & \multirow{2}{*}{-} & \multirow{2}{*}{-} & \multirow{2}{*}{-} & \multirow{2}{*}{-} & \multirow{2}{*}{-} & $\mathrm{Pt}-\mathrm{O}_{\mathrm{dis}}$ & 72.5 & 2.1 & \multirow{2}{*}{0.076} & 1.76 \\
\hline & & & & & & $\mathrm{PtO}_{x}$ & 73.7 & 2.7 & & 1.00 \\
\hline 500 & - & - & - & - & - & $\mathrm{PtO}_{x}$ & 73.7 & 2.9 & 0.037 & 1.11 \\
\hline
\end{tabular}

Dashes indicate that the $0.1-\mathrm{Pt} / \mathrm{SiO}_{2}$ sample was not treated in the reaction mixture at temperatures of 400 and $500^{\circ} \mathrm{C}$.

* The contact time of $\mathrm{Pt} / \mathrm{SiO}_{2}$ with a mixture of $32 \mathrm{mbar}$ of $\mathrm{NO}+32 \mathrm{mbar}$ of $\mathrm{O}_{2}$ was $5 \mathrm{~min}$ at all of the temperatures.

** FWHM is the full width at half maximum.

*** $\mathrm{Pt}-\mathrm{O}_{\mathrm{dis}}$ refers to the particles of platinum metal with oxygen dissolved in them.

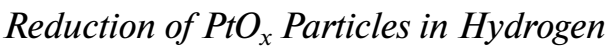

Figure 4 shows the $\mathrm{Pt} 4 f$ spectra of the $0.1-\mathrm{Pt} / \mathrm{SiO}_{2}$ (Fig. 4a) and 0.3-Pt/SiO 2 samples (Fig. 4b) measured in the course of the reduction of platinum oxide particles, which were formed as a result of the preliminary oxidation of the supported particles of platinum metal in $\mathrm{NO}+\mathrm{O}_{2}$, in hydrogen. The bottom spectra characterize the samples in the initial state, and the spectra arranged above them were obtained after treatment in the reaction mixture at a temperature that leads to the formation of platinum oxide $\left(\mathrm{PtO}_{x}\right)$ particles.

It is evident that the treatment of the $0.1-\mathrm{Pt} / \mathrm{SiO}_{2}$ sample in hydrogen in a temperature range from room temperature to $200^{\circ} \mathrm{C}$ did not have an effect on the spectral characteristics of the Pt $4 f$ line (Table 3, Fig. 4a). We can conclude that the particles of platinum oxide in the highly dispersed sample are not reduced by hydrogen under these conditions. As the reaction temperature was increased to $300^{\circ} \mathrm{C}$, the position, shape, and intensity of the line changed. In this case, the spectrum was described by two doublet lines, the most intense of which belonged to the metallic state. In this doublet, the lines have a characteristic asymmetric shape (Table 3 ). The binding energy $E_{\mathrm{b}}\left(\mathrm{Pt} 4 f_{7 / 2}\right)$ of $71.8 \mathrm{eV}$ is lower than that in the sample in the initial state $(72.2 \mathrm{eV})$. The weakening of the binding energy along with a decrease in the $\mathrm{Pt} / \mathrm{Si}$ atomic ratio by a factor of $\sim 2.5$ unambiguously indicate that the particle size of platinum increased after oxidative and reductive treatments. The components of the second less intense doublet line have a symmet- rical shape. The binding energy $E_{\mathrm{b}}\left(\mathrm{Pt} 4 f_{7 / 2}\right)=73.5 \mathrm{eV}$ of this line is almost the same as that in the sample with oxidized platinum particles. Note that, in this case, we did not observe the state of dissolved oxygen. This result seems expected because the reactivity of oxygen dissolved in platinum is higher than that of oxygen in platinum oxide [7].

After treatment in $\mathrm{NO}+\mathrm{O}_{2}$ at $500^{\circ} \mathrm{C}$, the $0.3-\mathrm{Pt} / \mathrm{SiO}_{2}$ sample was characterized by the spectrum that consisted of one wide doublet line, which belongs to the oxide particles of $\mathrm{PtO}_{x}$ (Fig. 4b). Based on the fact that the $0.3-\mathrm{Pt} / \mathrm{SiO}_{2}$ sample in the initial state had a wide platinum particle size distribution, we can hypothesize that the particles of $\mathrm{PtO}_{x}$ obtained as a result of interaction with $\mathrm{NO}+\mathrm{O}_{2}$ are also characterized by a wide size distribution. In contrast to the highly dispersed $0.1-\mathrm{Pt} / \mathrm{SiO}_{2}$ sample, in this case, the reduction of oxide begins even at room temperature upon the addition of hydrogen. In this case, the initial spectrum is split into two doublet lines, one of which with a binding energy of $74.1 \mathrm{eV}$ belongs to the oxide $\mathrm{PtO}_{x}$, and it is likely that the other with an asymmetric shape of doublet components and $E_{\mathrm{b}}\left(\mathrm{Pt} 4 f_{7 / 2}\right)=$ $72.5 \mathrm{eV}$ belongs to metallic platinum, which contains dissolved oxygen (Table 3, Fig. 4b). As the reduction temperature was increased to $100^{\circ} \mathrm{C}$, the qualitative composition of particles on the surface remained unchanged, but the fraction of platinum metal in the spectrum increased. Oxide was completely reduced to the metal after interaction with $\mathrm{H}_{2}$ at $200^{\circ} \mathrm{C}$. The binding energy $E_{\mathrm{b}}\left(\mathrm{Pt} 4 f_{7 / 2}\right)$ after reduction was $71.6 \mathrm{eV}$, 
(a)

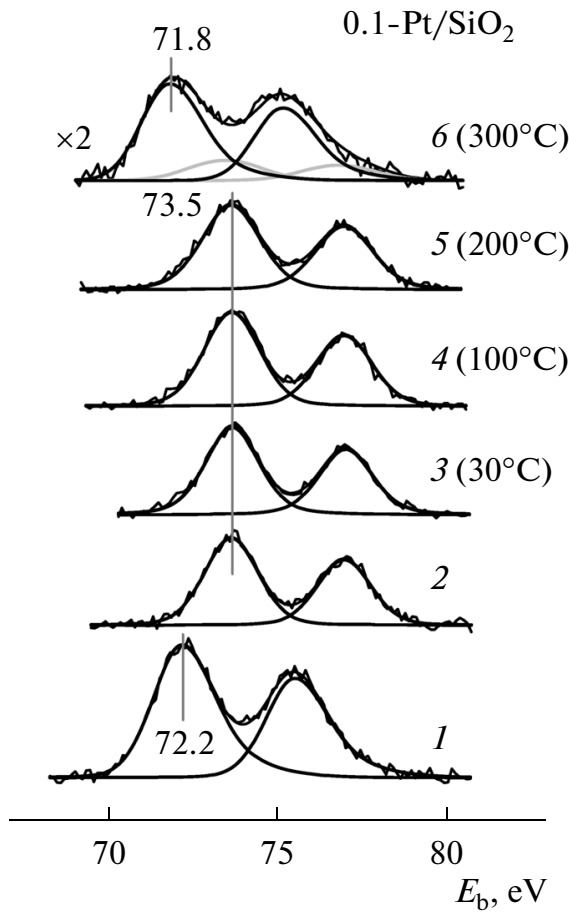

(b)

$$
0.3-\mathrm{Pt} / \mathrm{SiO}_{2}
$$
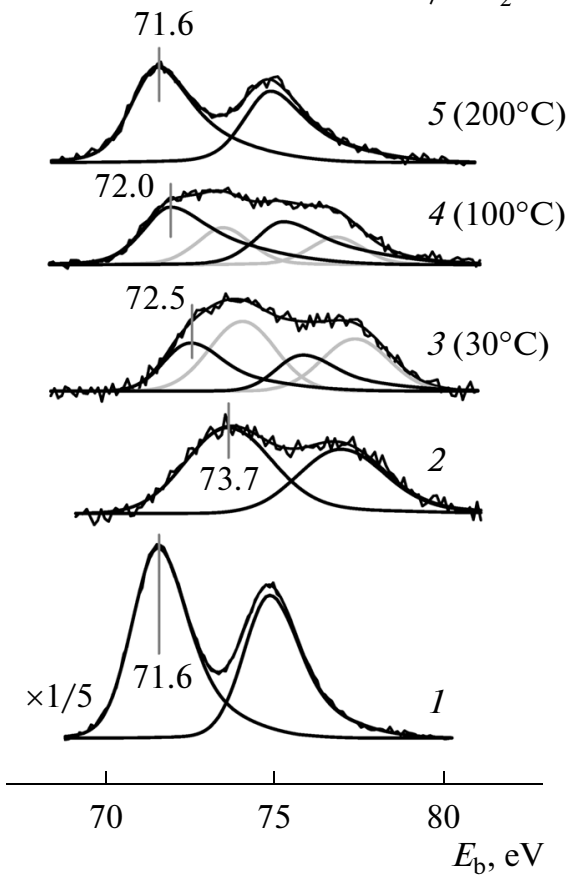

Fig. 4.Pt $f f$ XPS spectra of the (a) $0.1-\mathrm{Pt} / \mathrm{SiO}_{2}$ and (b) $0.3-\mathrm{Pt} / \mathrm{SiO}_{2}$ samples (1) before and (2) after the oxidation of supported platinum particles in a mixture of $\mathrm{NO}+\mathrm{O}_{2}$ at (a) 300 and (b) $500^{\circ} \mathrm{C}$ and the subsequent reduction in hydrogen at different temperatures. Pressure of hydrogen, 16 mbar; interaction time, 2 min.

which coincides with the value determined for the initial sample. Note that the $\mathrm{Pt} / \mathrm{Si}$ atomic ratio remained unchanged in the course of treatment in hydrogen. This fact allowed us to state that the particle size of supported platinum in the coarsely dispersed sample did not increase in the reduction process. It is interest- ing that, in the finely dispersed sample, agglomeration was observed both at the stage of oxidation and as a result of the reduction of platinum nanoparticles; in the coarsely dispersed sample, the agglomeration of particles was noticeable only at the first stage of oxidation.

Table 3. The temperature dependence of $\mathrm{Pt} 4 f_{7 / 2}$ line parameters and $\mathrm{Pt} / \mathrm{Si}$ atomic ratios on the contact of the $\mathrm{Pt} / \mathrm{SiO} \mathrm{S}_{2}$ samples oxidized in a mixture of $\mathrm{NO}+\mathrm{O}_{2}$ with hydrogen

\begin{tabular}{|c|c|c|c|c|c|c|c|c|c|c|}
\hline \multirow[b]{2}{*}{$T,{ }^{\circ} \mathrm{C}$} & \multicolumn{5}{|c|}{$0.1-\mathrm{Pt} / \mathrm{SiO}_{2}$} & \multicolumn{5}{|c|}{$0.3-\mathrm{Pt} / \mathrm{SiO}_{2}$} \\
\hline & state of $\mathrm{Pt}$ & $E_{\mathrm{b}}, \mathrm{eV}$ & $\begin{array}{c}\text { FWHM* } \\
\mathrm{eV}\end{array}$ & $\mathrm{Pt} / \mathrm{Si}$ & $\begin{array}{l}\text { asym- } \\
\text { metry }\end{array}$ & state of $\mathrm{Pt}$ & $E_{\mathrm{b}}, \mathrm{eV}$ & \begin{tabular}{|} 
FWHM $^{*}$, \\
$\mathrm{eV}$
\end{tabular} & $\mathrm{Pt} / \mathrm{Si}$ & $\begin{array}{l}\text { asym- } \\
\text { metry }\end{array}$ \\
\hline $\mathrm{PtO}_{x} / \mathrm{SiO}_{2}$ & $\mathrm{PtO}_{x}$ & 73.6 & 1.9 & 0.049 & 1.00 & $\mathrm{PtO}_{x}$ & 73.7 & 2.9 & 0.037 & 1.11 \\
\hline$\sim 30$ & $\mathrm{PtO}_{x}$ & 73.6 & 1.9 & 0.052 & 1.00 & $\begin{array}{l}\mathrm{PtO}_{x} \\
\mathrm{Pt}-\mathrm{O}_{\mathrm{dis}} * *\end{array}$ & $\begin{array}{l}74.1 \\
72.5\end{array}$ & $\begin{array}{l}2.3 \\
2.2\end{array}$ & 0.039 & $\begin{array}{l}1.00 \\
1.75\end{array}$ \\
\hline 100 & $\mathrm{PtO}_{x}$ & 73.6 & 1.9 & 0.054 & 1.00 & $\begin{array}{l}\mathrm{PtO}_{x} \\
\mathrm{Pt}-\mathrm{O}_{\text {dis }}\end{array}$ & $\begin{array}{l}73.5 \\
72.0 \\
\end{array}$ & $\begin{array}{l}2.4 \\
2.3 \\
\end{array}$ & 0.036 & $\begin{array}{l}1.00 \\
2.00\end{array}$ \\
\hline 200 & $\mathrm{PtO}_{x}$ & 73.6 & 2.0 & 0.052 & 1.00 & $\mathrm{Pt}^{0}$ & 71.6 & 2.2 & 0.040 & 1.69 \\
\hline 300 & $\begin{array}{l}\mathrm{PtO}_{x} \\
\mathrm{Pt}^{0}\end{array}$ & $\begin{array}{l}73.5 \\
71.8\end{array}$ & $\begin{array}{l}2.4 \\
2.2\end{array}$ & 0.041 & $\begin{array}{l}1.00 \\
1.24\end{array}$ & - & - & - & - & - \\
\hline
\end{tabular}

Dashes indicate that the $0.3-\mathrm{Pt} / \mathrm{SiO}_{2}$ sample was not treated in hydrogen at a temperature of $300^{\circ} \mathrm{C}$.

* FWHM is the full width at half maximum.

$* * \mathrm{Pt}-\mathrm{O}_{\text {dis }}$ refers to the particles of platinum metal with oxygen dissolved in them. 
Thus, in this work, we discovered that the interaction of the $\mathrm{Pt} / \mathrm{SiO}_{2}$ model supported catalysts with a mixture of $\mathrm{NO}+\mathrm{O}_{2}$ led to the dissolution of oxygen atoms in the bulk of platinum metal particles and to the formation of platinum oxide $\left(\mathrm{PtO}_{x}\right)$ particles. A comparative study of the samples of two types of catalysts, which differed in the amounts of supported platinum and particle size distributions, showed that the dissolution of oxygen in platinum readily occurred even at room temperature regardless of particle size. At the same time, the conversion of platinum metal particles into oxide particles is an activated process, and the oxidation temperature decreases with decreasing the particle size. The ease of the reduction of the oxidized platinum particles in hydrogen also depends on the particle size: the larger the oxide particles, the lower the temperature at which they can be returned to the metallic state.

\section{ACKNOWLEDGMENTS}

This work was supported by the Russian Science Foundation (project no. 14-23-00146).

\section{REFERENCES}

1. Lee, J.-H. and Kung, H.H., Catal. Lett., 1998, vol. 51, p. 1.

2. Olsson, L. and Fridell, E., J. Catal., 2002, vol. 210, p. 340 .

3. Benard, S., Retailleau, L., Gaillard, F., Vernoux, P., and Giroir-Fendler, A., Appl. Catal., B, 2005, vol. 55, p. 11.

4. Mulla, S.S., Chena, N., Cumaranatunge, L., Blau, G.E., Zemlyanov, D.Y., Delgass, W.N., Epling, W.S., and Ribeiro, F.H., J. Catal., 2006, vol. 241, p. 389.
5. Villani, K., Vermandel, W., Smets, K., Liang, D., van Tendeloo, G., and Martens, J.A., Environ. Sci. Technol., 2006, vol. 40, p. 2727.

6. Kalinkin, A.V., Sorokin, A.M., Smirnov, M.Yu., and Bukhtiyarov, V.I., Kinet. Catal., 2014, vol. 55, no. 3, p. 354 .

7. Smirnov, M.Yu., Vovk, E.I., Kalinkin, A.V., Pashis, A.V., and Bukhtiyarov, V.I., Kinet. Catal., 2012, vol. 53, no. 1, p. 117.

8. Smirnov, M.Yu., Kalinkin, A.V., and Bukhtiyarov, V.I., J. Struct. Chem., 2007, vol. 48, no. 6, p. 1053.

9. Smirnov, M.Yu., Kalinkin, A.V., Pashis, A.V., Sorokin, A.M., Noskov, A.S., Bukhtiyarov, V.I., Kharas, K.S., and Rodkin, M.A., Kinet. Catal., 2003, vol. 44, no. 4, p. 575.

10. Smirnov, M.Yu., Kalinkin, A.V., Pashis, A.V., Sorokin, A.M., Noskov, A.S., Kharas, K.C., and Bukhtiyarov, V.I., J. Phys. Chem. B, 2005, vol. 109, p. 11712.

11. Moulder, J.F., Stickle, W.F., Sobol, P.E., and Bomben, K.D., Handbook of X-Ray Photoelectron Spectroscopy, Eden Prairie, Minn.: PerkinElmer, 1992.

12. Mason, M.G., Phys. Rev. B: Condens. Matter, 1983, vol. 27, p. 748.

13. Hufner, S. and Wertheim, G.K., Phys. Rev. B: Condens. Matter, 1975, vol. 11, p. 678.

14. Stakheev, A.Yu., Shulga, Yu.M., Gaidai, N.A., Telegina, N.S., Tkachenko, O.P., Kustov, L.M., and Minachev, K.M., Mendeleev Commun., 2001, vol. 5, p. 165.

15. Kaushik, V.K., Z. Phys. Chem., 1991, vol. 173, p. 105.

16. Silvestre, A.J., Sepúlveda, E.A., Rodríguez, R.F., and Anderson, J.A., J. Catal., 2004, vol. 223, p. 179.

17. Zafeiratos, S., Papakonstantinou, G., Jacksic, M.M., and Neophytides, S.G., J. Catal., 2005, vol. 232, p. 127.

18. Huang, C.H., Wang, I.K., Lin, Y.M., Tseng, Y.H., and Lu, C.M., J. Mol. Catal. A: Chem., 2010, vol. 316, p. 163.

Translated by V. Makhlyarchuk 